\title{
Knowledge, attitude and belief about contraception in post-partum and post abortal women in a tertiary care centre
}

\author{
Shreya Thapa ${ }^{1}$, Anjali Rani ${ }^{1}$, C. P. Mishra ${ }^{2}$

\begin{abstract}
${ }^{1}$ Department of Obstetrics \& Gynecology, Institute of Medical Sciences, Banaras Hindu University, Varanasi, Uttar Pradesh, India

${ }^{2}$ Department of Community Health, Institute of Medical Sciences, Banaras Hindu University, Varanasi, Uttar Pradesh, India
\end{abstract}

Received: 30 May 2014

Accepted: 10 June 2014

*Correspondence:

Dr. Shreya Thapa,

E-mail: drshreyathapa@rediffmail.com

(C) 2014 Thapa S et al. This is an open-access article distributed under the terms of the Creative Commons Attribution Non-Commercial License, which permits unrestricted non-commercial use, distribution, and reproduction in any medium, provided the original work is properly cited.

\begin{abstract}
Background: In this modern era where women have achieved the highest positions in politics, corporate world and conquered the moon, on the other side she is still fighting for her right, i.e. health. For this the women should become economically independent. The concept of waiting for a son preference by the society should be discouraged. Postpartum and post abortal period are very crucial for a women especially for many of those belonging to the villages as this may be the only time she comes in contact with a health personnel. Hence counseling should be given to all patients at this time.

Methods: We conducted a cross-sectional study in the department of obstetrics and gynecology of sir Sunder Lal hospital between August 2013 to October 2013. 230 post-partum and post abortal women were interrogated and counseled about various methods of contraception. Awareness about emergency contraception pill and MTPill was also noted.

Results: Only 69\% had heard about various methods of contraception. IUCD and OCP were known to most patients. Most patients knew about contraception from television and doctors. After counseling 97\% patients wanted contraception. Most patients opted for IUCD, Barrier method and DepoProvera. 20\% patients knew about emergency contraception pill and $34.4 \%$ patients about MTPill.

Conclusions: There is lack of awareness of contraception, emergency contraception and medical abortion in women under study. Regular counseling is a must to all post-partum and post abortal women. Information should be provided about various methods and patients should be given a choice to choose the method of contraception.
\end{abstract}

Keywords: Contraception, Knowledge, Postpartum women, Post abortal women, MTPill, Emergency contraception

\section{INTRODUCTION}

The ability of women to control their own fertility is absolutely fundamental to women's empowerment and equality. When she is healthy, she can be more productive. And when her reproductive rights - including the right to decide the number, timing and spacing of her children and to make decisions regarding reproduction free of discrimination, coercion and violence - are promoted and protected, she has freedom to participate more fully and equally in society. For this the women should become economically independent and the concept of son preference by the society should be discouraged. Post-partum and post abortal period are very crucial for a woman as for many of those belonging to the villages, this may be the only time she comes in contact with a health personnel. Hence counseling should be given to all patients at this time. 
"The postpartum period is an important time to initiate contraception because women are accessing the healthcare system and might have increased motivation to avoid another pregnancy," writes Naomi K. Tepper, MD, from the division of reproductive health, national centre for chronic disease prevention and health promotion, CDC, and colleagues. "Ovulation can occur as early as 25 days postpartum among non-breastfeeding women, underscoring the importance of initiating contraception in the very early postpartum period". ${ }^{1}$ The fifth Millennium Development Goal (MDG) that aims to reduce infant deaths and improve maternal health while providing universal access to sexual and reproductive health services by 2015. The dynamics of contraceptive use among women in extended postpartum period, i.e. one year period after the birth of child, is of interest at the family planning programme level, since delay of use until the return of menstruation might subject women to the risk of unwanted pregnancy. An increase in contraceptive use during the postpartum period substantially reduces the rates of maternal and infant mortality by preventing unplanned and unwanted pregnancies, and spacing new pregnancies to at least two years after the previous birth. ${ }^{2}$ Furthermore, the largest proportion of women with an unmet need for contraception is found among those in their first year after childbirth. ${ }^{3}$ An analysis of data from 25 countries collected as part of the Demographic and Health Surveys (DHS) project found that mortality risks are elevated for both the previous child and for the newborn infant if birth intervals are shorter than expected. ${ }^{4}$ According to the report of NFHS-III, in India, 11 percent of births occur within 18 months of a previous birth and 28 percent occur within 24 months. More than 60 percent occur within three years of the previous birth and only 28 percent have an optimal birth interval of 3659 months. ${ }^{5}$ Thus in India, the higher proportion of unplanned pregnancies might be due to short birth intervals. In this context, the postpartum period is particularly important for initiating contraception to space births in a healthy manner.

In order to reduce the risk of adverse maternal, perinatal and infant outcomes, WHO (2006) recommended that the interval between a live birth and an attempt to the next pregnancy should be 24 months. ${ }^{6}$ Also Demographic and Health Survey (DHS) data analysis from 17 developing countries found that the risk of the newborn and infant dying decreases with increasing birth interval lengths up to 36 months. $^{7}$ In addition, short birth intervals $(<24$ months) also have a potential effect on the increased risk of maternal death and complications of pregnancies. ${ }^{8}$

According to the national family health survey 2005-06, Uttar Pradesh, India, the unmet need for family planning in currently married women of reproductive age group is $21.2 \%$. Among the common reasons for unmet need for family planning are inconvenient, unsatisfactory services, lack of information, fears about contraceptive side effects and opposition from husbands, relatives or others. ${ }^{9}$ Family planning and adoption of birth control measures reduces unintended pregnancies and unsafe abortions, averts maternal and new borne deaths, and leads to a decline in the number of women facing complications due to unsafe pregnancies would decline. ${ }^{10,11}$ Selecting appropriate contraceptive is a major concern in postpartum period.

\section{Aims and objectives}

To assess the knowledge, attitude and belief about contraception in post-partum and post abortal women in a tertiary care centre - sir Sunder Lal hospital, Banaras Hindu University, Varanasi, India.

\section{METHODS}

A cross sectional study was conducted in the department of obstetrics and gynecology of sir Sunder Lal hospital between August 2013 to October 2013. Sir Sunder Lal hospital is a tertiary care hospital in Banaras Hindu University, Varanasi. It caters services to a huge population of Uttar Pradesh and Bihar. A total of 230 post-partum and post abortal women were enrolled in the study after calculating from the pilot study conducted. The patients were interrogated on a pre-tested pre structured questionnaire. Ethical requirements of informed consent and confidentiality were ensured.

Their knowledge about the awareness of contraception and the various methods was assessed. They were counseled about various contraception methods available and allowed to choose a method of their choice for contraception. Patients were also interrogated about awareness of emergency contraception pill and medical termination of pregnancy pills.

Data was entered in Microsoft excel and SPSS version 15 was used for the statistical analysis.

\section{RESULTS}

\section{Socio-demographic details}

In this survey 230 immediate postpartum and post abortal women were taken. The age range was between 18-35 years (mean age - 26.4 with SD 4.2) given in Table 1.

Table 1: Socio-demographic profile of patients.

\begin{tabular}{|ll|}
\hline \multicolumn{2}{|c|}{\begin{tabular}{l} 
Muternal age (years) \\
\hline $15-24$
\end{tabular}} \\
\hline $25-34$ & $136(53 \%)$ \\
\hline $35-44$ & $18(7.8 \%)$ \\
\hline Parity & \\
\hline One live issue & $94(40.9 \%)$ \\
\hline $\begin{array}{l}\text { More than one } \\
\text { live issue }\end{array}$ & $136(59.1 \%)$ \\
\hline
\end{tabular}


We also divided patients based on modified Kuppuswamy scale and education level as shown in Table 2, 3. $10.9 \%$ were categorized as Kuppuswamy score $1,32.6 \%$ in group $2,47.4 \%$ in group $3,7.8 \%$ in group $4,1.3 \%$ in group 5 .

Table 2: Socioeconomic status.

\begin{tabular}{|ll|}
\hline Modified Kuppuswamy score & Number (\%) \\
\hline Upper (I) & $25(10.9 \%)$ \\
\hline Upper middle (II) & $75(32.6 \%)$ \\
\hline Middle/lower middle (III) & $109(47.4 \%)$ \\
\hline Lower/upper lower (IV) & $18(7.8 \%)$ \\
\hline Lower (V) & $3(1.3 \%)$ \\
\hline
\end{tabular}

Table 3: Educational status.

\begin{tabular}{|ll|}
\hline Education score & Number $(\%)$ \\
\hline Profession or honours & $14(6.1 \%)$ \\
\hline Graduate or post graduate & $1(0.4 \%)$ \\
\hline $\begin{array}{l}\text { Intermediate or post high } \\
\text { school diploma }\end{array}$ & $26(11.3 \%)$ \\
\hline High school certificate & $64(27.8 \%)$ \\
\hline Middle school certificate & $19(8.3 \%)$ \\
\hline Primary school certificate & $101(43.9 \%)$ \\
\hline Illiterate & $5(2.2 \%)$ \\
\hline Profession or honours & $14(6.1 \%)$ \\
\hline
\end{tabular}

\section{Knowledge about contraception}

Among the 230 women enrolled only $69 \%$ had heard about various methods of contraception. Figure 1 Only $65.95 \%$ women after one delivery or abortion had heard about contraception compared to $71.3 \%$ after two or more deliveries as shown in Table 4.

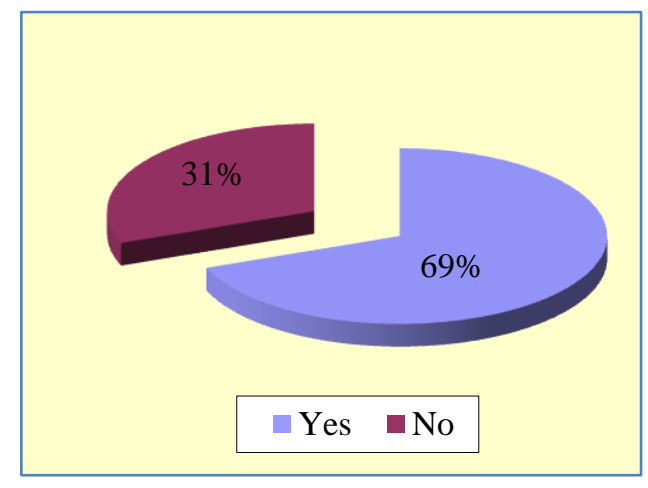

Figure 1: Knowledge about contraception.

Table 4: Knowledge based on parity.

\begin{tabular}{|llll|}
$\begin{array}{l}\text { Obstetric } \\
\text { history }\end{array}$ & Aware & Unaware & Total \\
\hline Para 1 & $62(65.95 \%)$ & 32 & 94 \\
\hline Multipara & $97(71.3 \%)$ & 39 & 136 \\
\hline & 159 & 71 & 230 \\
\hline
\end{tabular}

In the present study awareness according to education was also assessed, all professional were aware about contraception, $85.1 \%$ of graduates/post graduates, $73.7 \%$ of patients who studied till intermediate/diploma, $60.9 \%$ of high school, $42.3 \%$ of middle school and $28.57 \%$ of illiterate are aware about contraception. As shown in Table 5 and Figure 2 statistically significant variation was seen between education of the patient $\left(\mathrm{X}^{2}=38.371\right.$, degree of freedom $=6$ and $P$ value 0.001$)$.

Table 5: Knowledge based on education - statistically significant ( $P$ value 0.001 ).

\begin{tabular}{|llll|}
\hline Education & A ware & Unaware & Total \\
\hline Professional or honours & $5(100 \%)$ & 0 & 5 \\
\hline Graduate/post graduate & $86(85.1 \%)$ & 15 & 101 \\
\hline Intermediate/diploma & $14(73.7 \%)$ & 5 & 19 \\
\hline High school certificate & $39(60.9 \%)$ & 25 & 64 \\
\hline Middle school certificate & $11(42.3 \%)$ & 15 & 26 \\
\hline Primary school certificate & 0 & 1 & 1 \\
\hline Illiterate & $4(28.57 \%)$ & 10 & 14 \\
\hline
\end{tabular}

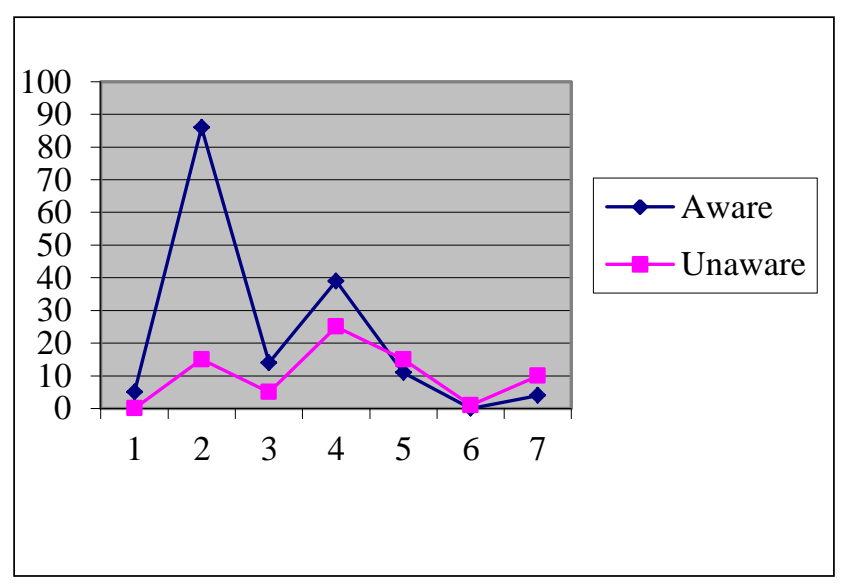

Figure 2: Knowledge based on education.

Their knowledge about the various methods of contraception according to socioeconomic status using modified Kuppuswamy score was assessed. On analysis $24(96 \%)$ of class I, $55(73.3 \%)$ of class II, $69(63.3 \%)$ of class III, $10(55.5 \%)$ of class IV and $1(33.3 \%)$ of class V were aware. Statistically significant value was seen between the different socioeconomic classes. $\left(\mathrm{X}^{2}\right.$ value $=$ 14.169, degree of freedom $=4$ and a significant $\mathrm{P}$ value of $<0.002)$.

Table 6: Knowledge based on socio economic status statistically significant $(P$ value $<\mathbf{0 . 0 0 2})$.

\begin{tabular}{|llll|}
\hline Social class & A ware & Unaware & Total \\
\hline Upper (I) & $24(96 \%)$ & 1 & 25 \\
\hline Upper middle (II) & $55(73.3 \%)$ & 20 & 75 \\
\hline Middle/lower middle (III) & $69(63.3 \%)$ & 40 & 109 \\
\hline Lower/upper lower (IV) & $10(55.5 \%)$ & 8 & 18 \\
\hline Lower (V) & $1(33.3 \%)$ & 2 & 3 \\
\hline & 159 & 71 & 230 \\
\hline
\end{tabular}


Their awareness according to the occupation of wife is depicted in Table 7 . Out of 213 housewives only 143 (67\%) had heard about contraception, compared to $93.3 \%$ (14 out of 15 women) in skilled group (Tailor, clerk).

Table 7: Knowledge based on occupation.

\begin{tabular}{|llll|}
\hline Occupation & Aware & Unaware & Total \\
\hline Housewife & $143(67.1 \%)$ & 70 & 213 \\
\hline Skilled personnel & $14(93.3 \%)$ & 1 & 15 \\
\hline Professional & $2(100 \%)$ & 0 & 2 \\
\hline & 159 & 71 & 230 \\
\hline
\end{tabular}

Most patients knew about contraception from television (36\%), $23 \%$ from doctor, $22 \%$ from family members, $12 \%$ from books and newspapers. Only $6 \%$ knew from ASHA as seen in Figure 3.

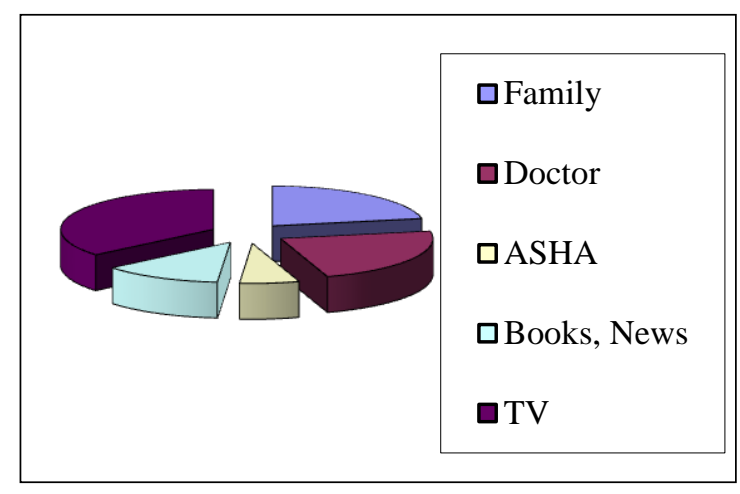

Figure 3: Source of knowledge

Among the inpatients who had knowledge about contraception $(n=159)$, survey was also carried to know the methods known to them. IUCD was known to $83.65 \%$, barrier method $-70.44 \%$, oral contraceptive pills - $45.28 \%$, lactational amenorrhea- 1\%, DepoProvera $38.3 \%$ and safe method was known to $2.5 \%$ patients as given in Table 8.

Table 8: Knowledge about the various methods of contraception among the population aware of contraception.

\begin{tabular}{|ll|}
\hline Method of contraception & Number (\%) \\
\hline IUCD & $133(83.65 \%)$ \\
\hline Barrier method & $112(70.44 \%)$ \\
\hline Oral contraception pills (POP) & $72(45.28 \%)$ \\
\hline DMPA & $61(38.3 \%)$ \\
\hline Lactational Amenorrhea & $15(1 \%)$ \\
\hline Safe method & $4(2.5 \%)$ \\
\hline
\end{tabular}

After counseling on post-partum contraception and giving them an informed choice $97 \%$ patients wanted contraception. Choices preferred were $33.6 \%$ opted for IUCD, 20\% for barrier method, 26.5\% opted for DepoProvera, $10 \%$ for progesterone pills safe method $3 \%$. However $3 \%$ patients did not want any method.
Table 9: After counselling the various methods of contraception chosen.

\begin{tabular}{|ll|}
\hline Method of contraception & Number (\%) \\
\hline IUCD & $77(33.6 \%)$ \\
\hline Barrier method & $46(20 \%)$ \\
\hline Oral contraception pills (POP) & $23(10 \%)$ \\
\hline DMPA & $61(26.5 \%)$ \\
\hline Lactational Amenorrhea & $9(3.9 \%)$ \\
\hline Safe Method & $7(3 \%)$ \\
\hline No method & $7(3 \%)$ \\
\hline
\end{tabular}

The key factors which influenced the knowledge of contraception were education of wife ( $\mathrm{P}$ score <0.001) and socioeconomic status measured by the modified Kuppuswamy score (P score $<0.02$ ).

The various beliefs that people had towards contraception were as follows. Copper $\mathrm{T}$ was thought to cause polymenorrhagia by $18.3 \%$ patients, infection by $3 \%$ patients, weakness by $3 \%$ and white discharge and lower abdominal pain by migration to abdomen by $2.2 \%$ patients and cancer by $1.3 \%$ patients. Oral contraception pill causes polymenorrhagia was thought by 5 patients, infertility by 1 patient and carcinoma by 3 patients.

Table 10: Knowledge about emergency contraception pill.

\begin{tabular}{|c|c|c|c|c|}
\hline & \multicolumn{2}{|c|}{ Emergency pill } & \multirow{2}{*}{ Total } \\
\hline & & $\mathbf{N}$ & $\mathbf{Y}$ & \\
\hline \multicolumn{5}{|c|}{ Knowledge } \\
\hline \multirow[t]{2}{*}{$\mathrm{N}$} & Count & 65 & 6 & 71 \\
\hline & $\begin{array}{l}\% \text { within } \\
\text { knowledge }\end{array}$ & $91.5 \%$ & $8.5 \%$ & $100.0 \%$ \\
\hline \multirow[t]{2}{*}{$\mathrm{Y}$} & Count & 119 & 40 & 159 \\
\hline & $\begin{array}{l}\% \text { within } \\
\text { knowledge }\end{array}$ & $74.8 \%$ & $25.2 \%$ & $100.0 \%$ \\
\hline \multirow[t]{2}{*}{ Total } & Count & 184 & 46 & 230 \\
\hline & $\begin{array}{l}\% \text { within } \\
\text { knowledge }\end{array}$ & $80.0 \%$ & $20.0 \%$ & $100.0 \%$ \\
\hline
\end{tabular}

Table 11: Knowledge about medical termination of contraception pills.

\begin{tabular}{|c|c|c|c|c|}
\hline & \multicolumn{2}{|l|}{ MTP } & \multirow{2}{*}{ Total } \\
\hline & & $\mathbf{N}$ & $\mathbf{Y}$ & \\
\hline \multicolumn{5}{|c|}{ Knowledge } \\
\hline \multirow[t]{2}{*}{$\mathrm{N}$} & Count & 55 & 16 & 71 \\
\hline & $\begin{array}{l}\% \text { within } \\
\text { knowledge }\end{array}$ & $77.5 \%$ & $22.5 \%$ & $100.0 \%$ \\
\hline \multirow[t]{2}{*}{$\mathrm{Y}$} & Count & 96 & 63 & 159 \\
\hline & $\begin{array}{l}\% \text { within } \\
\text { knowledge }\end{array}$ & $60.4 \%$ & $39.6 \%$ & $100.0 \%$ \\
\hline \multirow[t]{2}{*}{ Total } & Count & 151 & 79 & 230 \\
\hline & $\begin{array}{l}\% \text { within } \\
\text { knowledge }\end{array}$ & $65.7 \%$ & $34.3 \%$ & $100.0 \%$ \\
\hline
\end{tabular}


Emergency contraception pill was known to only $20 \%$ (46 out of 230 patients) Table 11 . Of the 71 patients who were not aware about the methods of contraception, $8.5 \%$ knew about emergency contraceptive pills. Medical termination of pregnancy was known to $34.3 \%$ (79 out of 230 patients).

\section{DISCUSSION}

This study is first of its kind as we could not find any previous study reporting on the awareness and knowledge on contraception in post-partum or post abortal women. Among the 230 women enrolled in our study only $69 \%$ had heard about various methods of contraception. IUCD was known to $45 \%$ patients. Oral contraceptive pills $30 \%$, barrier method $-42 \%$, lactational amenorrhea- $1 \%$, Depo-Provera - $17 \%$ and safe method was known to $1 \%$ patients. Main source of information was from television and doctor. After giving post-partum contraception counseling - $97 \%$ patients were willing to use contraception. Choices preferred were $33.6 \%$ opted for IUCD, 20\% for barrier method, 26.5\% Depo-Provera, Progesterone pills - 10\%, barrier method - 20\%, lactational amenorrhea $-3.9 \%$ and safe method $-3 \%$. However $3 \%$ patients chose abstinence.

Emergency contraception pill was known to only $20 \%$ of patients and medical termination of pregnancy pill was known to $34.4 \%$ patients.

In a study among the rural females of Bareilly district by Syed Esam Mahmood the prevalence of postpartum contraceptive method use was $13.8 \% .^{12}$ Another study in rural Uttar Pradesh by Goel et al. (2010) reported a much higher figure $28.0 \%$. ${ }^{11}$ Higher postpartum contraceptive prevalence $(41.0 \%)$ has also been reported by the population council study. ${ }^{13}$ Around $20.0 \%$ of post-partum contraception has been reported by NFHS-3 (2005-06) for rural Uttar Pradesh. ${ }^{1}$

Another study on contraceptive use among married women in a slum in Mumbai by Kiran G. Makade stated $87.7 \%$ of women were aware of at least one method of contraception. $68.4 \%$ women were using a contraceptive at the time of study. Out of 342 women, $87.71 \%$ were aware about Oral Contraceptive Pills (OCP) and $\mathrm{Cu}-\mathrm{T}$, followed by female sterilization and condoms which was known to $80.4 \%$ and $77.5 \%$ women respectively. ${ }^{15}$ Only $12.67 \%$ were aware of emergency pills $78.94 \%$ of the study population was aware of medical termination of pregnancy. Very low awareness of emergency contraception has also been observed in other studies. ${ }^{23-27}$

In our study, The key factors which influenced the knowledge of contraception were education of wife ( $P$ score $<0.001)$ and socioeconomic status measured by the modified Kuppuswamy score (P score $<0.02$ ). Significant association between contraceptive acceptance and type of family, socioeconomic status and age at marriage was observed in a study conducted among women of reproductive age in rural Maharasthra. ${ }^{16}$ Similar findings have been reported by other Indian studies. ${ }^{16,17}$ Contraceptive use was higher $(19.1 \%)$ among the females who were delivered at a hospital/health centre as compared to those delivered at home $(8.3 \%)$. This can be attributed to the antenatal and postnatal family planning advice given to patients delivered at a hospital/health centre.

In a study conducted in Mexico, women who received family planning advice during prenatal care were more likely to use a contraceptive than were those who did not receive such advice. Strong associations between maternal health care and family planning practice have been established in previous studies. ${ }^{18-22}$

\section{CONCLUSION}

There is lack of awareness of contraception in postpartum and post abortal patients. Regular counseling is a must to all pregnant women from every health centre in a village to super speciality centres in cities. Information should be provided about various methods of contraception and patients should be able to choose a method of their choice. There is lack of awareness of emergency contraception and medical termination of pregnancy in post-partum and post abortal women under study.

The limitation of this study was that only a group of patients who seeked health care in a tertiary centre were interviewed. Hence the findings in this study cannot be generalized to the state or to India as a whole. Our study reveals that education level and socioeconomic status are the major limiting factors in accepting family planning methods. There is a need for proper promotion of spacing methods by policy makers and field workers and motivation of couples to accept them.

Women who have recently given birth need augmented attention from family planning and reproductive health programs if they are to reduce their numbers of unwanted births and abortions and to lengthen subsequent birth intervals. Prenatal visits, delivery services and subsequent health system contacts are promising avenues for reaching postpartum women with an unmet need for and a desire to use family planning services. ${ }^{28}$

While it is essential to device programmes to spread awareness among women to use contraception to limit births, it is also very essential to effectively device and implement postpartum family planning programmes in India by integrating them with maternal and child health services. When postpartum family planning is presented as a part of maternal and child-health services, it will have a broader cultural acceptance. In addition, women who receive counseling during hospital stay for delivery are more likely to use contraceptives in postpartum period. It is also seen that women who receive counseling during hospital stay for delivery are more likely to use contraceptives in postpartum period. Thus, there is a need 
to observe more closely the role of family planning policies and health care providers in effectively generating motivation and knowledge among Indian women to use contraceptives in postpartum period. It is also very important to target the poor and less educated women for the success of postpartum family planning programmes in India.

\section{ACKNOWLEDGEMENTS}

I would like to thank Miss Jaya, research scholar in the department of community medicine, institute of medical sciences for helping me in analyzing my data using SPSS.

\section{Funding: No funding sources}

Conflict of interest: None declared

Ethical approval: The study was approved by the institutional ethics committee

\section{REFERENCES}

1. Laurie Barclay. CDC updates guidelines for postpartum contraceptive use. Medscape, 2011. Available http://www.medscape.com/viewarticle/746177.

2. R. Vernon. Meeting the family planning needs of postpartum women. Stud Family Planning. 2009;40(3):235-45.

3. John A. Ross, William L. Winfrey. Contraceptive use, intention to use and unmet need during the extended postpartum period. Int Family Planning Persp. 2001;27(1):20-7.

4. Hobcraft J. Demographic and health surveys. In: Hobcraft J, eds. The Health Rationale for Family Planning: Timing of Births and Child Survival. 1st ed. New York: United Nations; 1994: 112.

5. International Institute for Population Sciences (IIPS). The third national family health survey (NFHS-3), India, 2005-06. Int Insti Popul Sci Mumbai. 2007;2:1-168.

6. World Health Organization. Report of a WHO technical consultation on birth spacing. In: WHO, eds. WHO Report. Geneva: WHO; 2006: 1-37.

7. Rutstein, SO. Effects of preceding birth intervals on neonatal, infant and under-five years mortality and nutritional status in developing countries: evidence from the demographic and health surveys. Int $\mathbf{J}$ Gynecol Obstet. 2005;89:S7-24.

8. Conde-Agudelo A, Belizán J. Maternal morbidity and mortality associated with interpregnancy interval. Br Me J. 2000;321:1255-9.

9. Husain, Zakir, Dutta, Mousumi, Ghosh. Population report: meeting unmet need, new strategies. Series J. 1997 Jun;43:3-9.

10. MPRA Paper No. 30790. Contraceptive use among illiterate women in India: does proximate illiteracy matter? Available at: http://mpra.ub.unimuenchen.de/30790/.
11. Goel S, Bhatnagar I, Khan ME, Hazra A. Increasing postpartum contraception in rural Uttar Pradesh. J Family Welfare. 2010;56:57-64.

12. Syed Esam Mahmood, Anurag Srivastava, Ved Prakash Shrotriya, Iram Shaifali, Payal Mishra. Postpartum contraceptive use in rural Bareilly. Indian J Comm Health. 2011 Jul-Dec;23(2):56-7.

13. Agarwal AK. Social classification: The need to update in the present scenario. Indian J Comm Med. 2008;33:50-1.

14. International Institute for Population Sciences and Macro International. National Family Health Survey3, 2005-2006. Int Insti Popul Sci Mumbai. 2007;2:1168.

15. Kiran G. Makade, Manasi Padhyegurjar, Shekhar B. Padhyegurjar. Study of contraceptive use among married women in a slum in Mumbai. National $\mathbf{J}$ Comm Med. 2012 Jan-Mar;3(1):40-3.

16. Murarkar SK, Soundale SG. Epidemiological correlates of contraceptive prevalence in married women of reproductive age group in rural area. National J Comm Med. 2011;2(1):78-81.

17. Chankapa YD, Tsering D, Kar S, Basu M, Pal R. Socio-demographic variables of contraceptive practice in Sikkim. J Pharm Bioall Sci. 2011;3(3):368-74.

18. Barber SL. Family planning advice and postpartum contraceptive use among low-income women in Mexico. Int Family Planning Persp. 2007;33(1):6-12.

19. Hotchkiss DR, Magnani, RJ, Rous JJ, Azelmat M, Mroz TA, Heikel J. The effects of maternal-child health service utilization on subsequent contraceptive use in Morocco. J Biosoc Sci. 1999;31(2):145-65.

20. Zerai A, Tsui AO. The relationship between prenatal care and subsequent modern contraceptive use in Bolivia, Egypt and Thailand. Afr J Reprod Health. 2001;5(2):68-82.

21. Ahmed S, Mosley WH. Simultaneity in the use of maternal-child health care and contraceptives: evidence from developing countries. Demography. 2002;39(1):75-93.

22. Hotchkiss DR, Rous JJ, Seiber EE, Berruti AA. Is maternal and child health service use a causal gateway to subsequent contraceptive use? A multicountry study. Popul Res Policy Rev. 2005;24(6):543-71.

23. Chopra S, Dhaliwal L. Knowledge, attitude and practices of contraception in urban population of North India. Arch Gynecol Obstet. 2010;281:273-7.

24. Reddy RS, Premarajan KC, Narayan KA, Mishra AK. Rapid appraisal of knowledge, attitude and practices related to family planning methods among men within 5 years of married life. Indian J Prev Soc Med. 2003 Jan-June;34(1\&2):63-7.

25. Mao J. Knowledge, attitude and practice of family planning: a study of Tezu Village, Manipur (India). Intern J Biol Anthropol. 2007;1(1):1-9.

26. Basu S, Kapoor A, Basu SK. knowledge, attitude and prevention of family planning among tribals. J Family Welfare. 2004 June;50(1):24-30. 
27. Tripathi R, Rathore AM, Sachdeva J. Emergency contraception: knowledge, attitude, and practices among health care providers in North India. J Obstet Gynecol Res. 2003 Jun;29(3):142-6.

28. John A. Ross, William L. Winfrey. Contraceptive use, intention to use and unmet need during the extended postpartum period. Int Family Planning Persp. 2001;27(1):20-7.

DOI: $10.5455 / 2320-1770 . i j r \operatorname{cog} 20140912$

Cite this article as: Thapa S, Rani A, Mishra CP.

Knowledge, attitude and belief about contraception in post-partum and post abortal women in a tertiary care centre. Int J Reprod Contracept Obstet

Gynecol 2014;3:533-9. 